\section{Synergistic Activity of Imidazole Derivatives with Permethrin against Susceptible Houseflies}

\author{
Koichiro WATANABE, Ryuko TAKEYA, \\ Naotaka YAMADA and Eiichi KUWANO*
}

Laboratory of Pesticide Chemistry, Department of Agricultural Chemistry, Kyushu University, Higashi-ku, Fukuoka 812-8581, Japan

(Received September 4, 1997 ; Accepted January 5, 1998)

\section{INTRODUCTION}

The many functions of cytochrome P450 monooxygenases (P450s) are well known in insects in which they function in the activation and detoxication of exogenous compounds, in the metabolism of endogenous compounds such as hormones and pheromones, and in adaptation to host plants. ${ }^{1)}$ It appears that specific P450 inhibitors are useful not only as a probe for elucidating the functions of P450s but also to develop a new insect control agent. The remarkable potency of a number of 1,5-disubstituted imidazoles as inhibitors of P450s has recently been published. 5-(3-Benzyloxyphenyl)1-isobutylimidazole ( $\mathrm{TH}-27$ ) inhibited the last step in juvenile hormone III biosynthesis, the $\mathrm{P} 450$ responsible for the epoxidation of methyl farnesoate, and caused a massive accumulation of the P450 substrate methyl farnesoate. ${ }^{2)}$ Moreover, 1-benzyl-5-[(E)-2,6-dimethyl-1,7-heptadienyl]imidazole (KK-42), which inhibits ecdysteroid synthesis in vitro in the prothoracic glands of Bombyx mori ${ }^{3}$. and Locusta migratoria ${ }^{4)}$ has been found to inhibit C-22 hydrolase, a $\mathrm{P} 450$, involved in ecdysteroid biosynthesis in ovarian follicle cells of L. migratoria. ${ }^{5)}$ 5-(2-Ethoxyphenyl)-1neopentylimidazole (KK-110), which induces precocious metamorphosis in B. mori $^{6}{ }^{6}$ and Neobelliaria bullata ${ }^{7)}$ inhibited P450-dependent microsomal ecdysone 20monooxygenase of fat bodies in $N$. bullata larvae. ${ }^{8)}$

On the other hand, several of the 1-aryl and 1alkylimidazoles were first observed to inhibit $\mathbf{P} 450$ s involved in the metabolism of carbamate insecticides and to be effective carbamate synergists to houseflies. ${ }^{9,10)}$ In the 1-alkylimidazole series, analogs with 8-10 carbon alkyl chains were the most active both in terms of in vivo synergism of carbaryl against houseflies and in vitro inhibition of aldrin epoxidation in rat liver microsomes, indicating the importance of lipophilic character in the compounds to interact with P450s. ${ }^{10)}$ In view of the extraordinary potency of the

\footnotetext{
* To whom correspondence should be addressed.
}

imidazoles as P450 inhibitors, ${ }^{11)}$ we examined the synergistic activity of a variety of 1,5-disubstituted and 1-substituted imidazoles which have been discovered as insect growth regulators. ${ }^{12,13)}$ In addition, we synthesized a new series of 1-(4-alkyloxyphenyl)imidazoles and evaluated their synergistic activity. In the present paper, we report synergism of permethrin by imidazoles in susceptible houseflies.

\section{MATERIALS AND METHODS}

\section{Chemicals}

Permethrin (97\%) was kindly supplied by Earth Biochemical Co. The 1,5-disubstituted and 1-alkylimidazoles were synthesized according to the procedures reported previously. ${ }^{12,13)}$ The 1-(4-alkyloxyphenyl)imidazoles were prepared by alkylation of 1-(4-hydroxyphenyl)imidazole with the appropriate alkyl halide in $N, N$-dimethylformamide (DMF) using sodium hydride as a base. The following procedure for the preparation of 1-(4-benzyloxyphenyl)imidazole (5) is typical. To a suspension of $0.33 \mathrm{~g}$ of sodium hydride $\left(60 \%\right.$ in oil) in $10 \mathrm{ml}$ of DMF at $0-5^{\circ} \mathrm{C}$ was added 1 $\mathrm{g}$ of 1-(4-hydroxyphenyl)imidazole and the mixture was stirred for $1 \mathrm{hr}$ at room temperature. To the ice-cooled mixture was added $0.79 \mathrm{~g}$ of benzyl chloride. After stirring for $24 \mathrm{hr}$ at room temperature, $50 \mathrm{ml}$ of water was added to the mixture. The resulting precipitate was collected by filtration, washed with water, and recrystallized from diisopropyl ether to give $0.4 \mathrm{~g}(26 \%)$ of $5, \mathrm{mp} 110-111^{\circ} \mathrm{C}$. NMR $\left(\mathrm{CDCl}_{3}\right) \delta: 5.11(2 \mathrm{H}$, s, $\left.\mathrm{CH}_{2}\right), 7.06(2 \mathrm{H}, \mathrm{d}, J=8.5 \mathrm{~Hz}$, phenyl), $7.19(2 \mathrm{H}, \mathrm{d}, J=8.5$ $\mathrm{Hz}$, phenyl), 7.22-7.48 (7H, m, phenyl and imidazolyl), 7.76 (1H, s, imidazolyl). Anal. Found: C, 76.48; H, 5.64; N, 10.95\%. Calcd. for $\mathrm{C}_{16} \mathrm{H}_{14} \mathrm{~N}_{2} \mathrm{O}$ : C, 76.80; H, 5.60; N, 11.20\%.

\section{Bioassay}

Three-to-four-day-old female houseflies (Musca domestica L., WHO's standard susceptible strain) were used for the insecticidal assay. Testing was carried out by topical application of $1 \mu \mathrm{l}$ of acetone solution containing permethrin and synergist to the dorsal thoraces of the flies. Twenty flies were used at each concentration. The treated insects were provided with sugar solution and held at $25 \pm 1{ }^{\circ} \mathrm{C}$. Mortality was recorded $24 \mathrm{hr}$ after treatment. The synergistic activity was first evaluated by applying a mixture of permethrin $(0.01$ $\mu \mathrm{g} / \mathrm{fly})$ and a test compound $(5 \mu \mathrm{g} / \mathrm{fly})$. The synergistic ratio (ratio between $L_{50}$ of permethrin alone to $L_{50}$ of permethrin applied with synergist ${ }^{14)}$ was determined by applying permethrin-synergist combinations at 1 to 10 ratio. The $\mathrm{LD}_{50}$ value of permethrin alone was $3.1 \mu \mathrm{g} / \mathrm{g}$ against the houseflies used.

\section{RESULTS AND DISCUSSION}

Table 1 shows the insecticidal activity of a mixture of permethrin $(0.01 \mu \mathrm{g})$ and a test compound $(5 \mu \mathrm{g})$ against 
Table 1 Synergistic activity of a variety of imidazoles with permethrin $(0.01 \mu \mathrm{g} / \mathrm{fly})$ against susceptible houseflies.

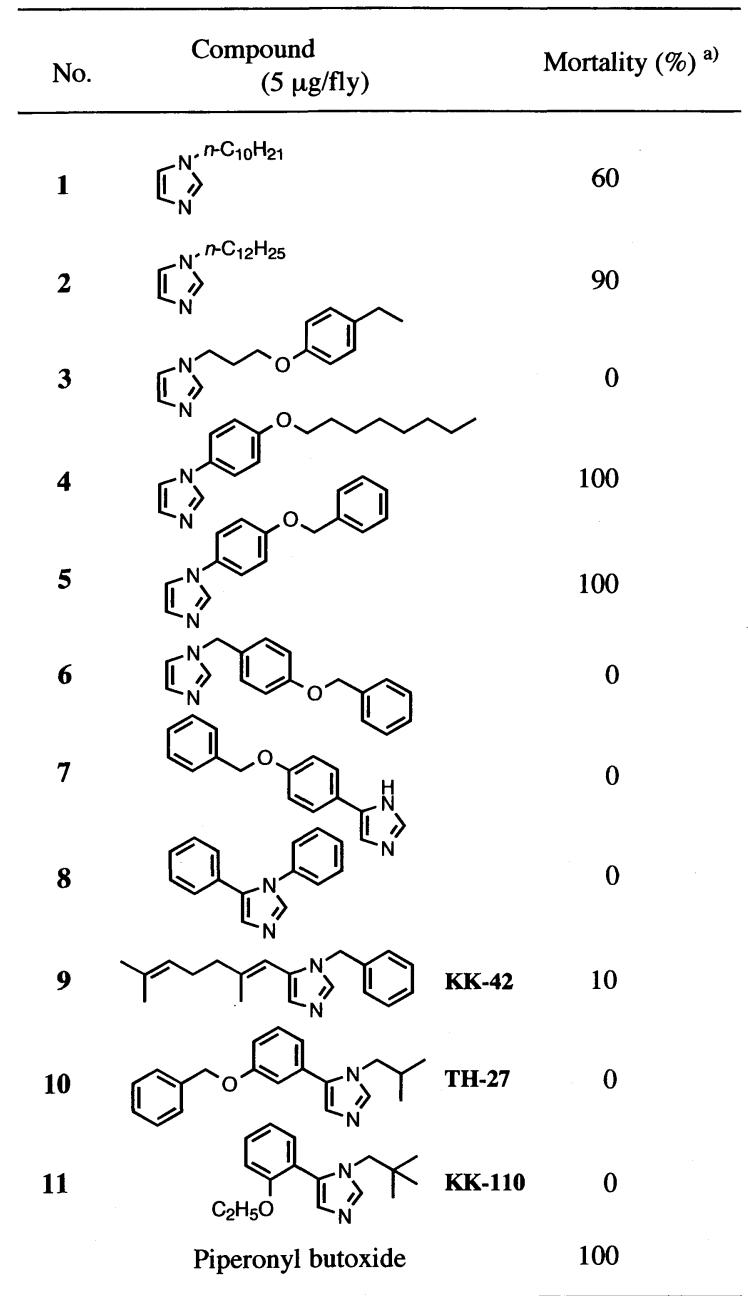

a) Permethrin and each imidazole were not toxic alone at $0.01 \mu \mathrm{g}$ and $5 \mu \mathrm{g}$, respectively.

susceptible houseflies. Permethrin alone was not toxic at $0.01 \mu \mathrm{g}$. When applied alone, all imidazole compounds examined were non-toxic at $5 \mu \mathrm{g}$. 1-Decyl- and 1dodecylimidazoles (1 and $\mathbf{2}$ ), which are effective synergists against carbaryl, ${ }^{10}$ exhibited some synergistic activity with permethrin. The phenoxypropyl analog 3, which induces precocious metamorphosis in $B$. mori larvae as well as compounds 1 and $2,{ }^{13)}$ was inactive as a synergist. 1-(4Octyloxyphenyl)- and 1-(4-benzyloxyphenyl)imidazoles (4 and 5) were as potent as piperonyl butoxide in the synergistic activity. It is noteworthy that compound $\mathbf{6}$ with one extra carbon atom between the imidazole and the benzene ring did not synergize the action of permethrin. 4-(4Benzyloxyphenyl)imidazole (7), a structural isomer of $\mathbf{5}$, was inactive as a synergist, suggesting that the location of a 4benzyloxyphenyl group was important for the activity. 1,5-Diphenylimidazole (8), which has been reported to
Table 2 Synergistic activity of 1-substituted imidazoles with permethrin against susceptible houseflies.

Synergistic ratio ${ }^{\text {a) }}$

inhibit the epoxidation of aldrin in rat liver microsomes and armyworm guts preparations, ${ }^{11)}$ did not show any synergistic activity with permethrin. 1,5-Disubstituted imidazoles such as KK-42, TH-27 and KK-110 were not effective synergists of permethrin, indicating some selectivity for the specific P450s.

Since the benzyloxyphenyl analog 5 showed considerably high synergistic activity, the analogs having a halogen atom at the benzyl group were synthesized and evaluated. Table 2 presents the synergistic ratios of the representative imidazoles. Compound $\mathbf{4}$ exhibited activity comparable to that of piperonyl butoxide which was twice as active as compound $\mathbf{2}$. Compound 5 was slightly less active than piperonyl butoxide. The introduction of a fluoro substituent into the benzyl group irrespective of its position decreased the activity in comparison with that of compound 5 . There was little difference in activity between the 2-fluorobenzyl analog 12 and 2chlorobenzyl analog 15.

Based on the strong capacity of 1-substituted imidazoles to bind to the prosthetic heme iron of $\mathrm{P} 450,{ }^{10)}$ it would appear that 1-alkyloxyphenylimidazoles in this article inhibit P450s involved in the metabolism of permethrin. The activity of imidazoles as P450 inhibitors seems to be dependent on the 
ability to bind to the hydrophobic regions close to the active site, the heme iron, of the enzyme. It might be possible to develop P450 inhibitors with reasonable selectivity by structural modification of the substituents on the imidazole ring.

\section{ACKNOWLEDGMENTS}

We thank Dr. M. Kamei of Earth Biochemical Co. for providing permethrin. This work was supported in part by Grant-inAid for Scientific Research 07556081 from the Ministry of Education, Science, Sports and Culture of Japan.

\section{REFERENCES}

1) E. Hodgson: Insect Biochem. 13, 237 (1983)

2) G. C. Unnithan, J. F. Andersen, T. Hisano, E. Kuwano \& R. Feyereisen: Pestic. Sci. 43, 13 (1995)

3) O. Yamashita, K. Kadono-Okuda, E. Kuwano \& M. Eto: Agric. Biol. Chem. 51, 2295 (1987)

4) J. P. Roussel, M. Kiuchi, H. Akai \& E. Kuwano: C.R. Acad. Sci. Paris, Serie III 305, 141 (1987)

5) T. D. Jarvis, F. G. P. Earley \& H. H. Rees: Pestic. Biochem. Physiol. 48, 153 (1994)

6) E. Kuwano, M. Kikuchi \& M. Eto: Agric. Biol. Chem. 52, 1619 (1988)

7) B. Darvas, E. Kuwano, M. Eto, M. H. Tag El-Din \& T. Timar: Agric. Biol. Chem. 54, 3045 (1990)

8) B. Darvas, H. H. Rees, N. Hoggard, M. H. Tag El-Din, E. Kuwano, I. Belai \& T. Timar: Pestic. Sci. 36, 135 (1992)

9) C. F. Wilkinson, K. Hetnarski \& L. J. Hicks: Pestic.
Biochem. Physiol. 4, 299 (1974)

10) C. F. Wilkinson, K. Hetnarski, G. P. Cantwell \& F. J. Di Carlo: Biochem. Pharmac. 23, 2377 (1974)

11) T. D. Rogerson, C. F. Wilkinson \& K. Hetnarski: Biochem. Pharmac. 26, 1039 (1977)

12) E. Kuwano, T. Hisano, M. Eto, K. Suzuki, G. C. Unnithan \& W. S. Bowers: Pestic. Sci. 34, 263 (1992)

13) K. Shimazu, M. Shimizu, K. Suzuki \& E. Kuwano: J. Pesticide Sci. 21, 337 (1996)

14) R. M. Sacher, R. L. Metcalf \& T. R. Fukuto: J. Agric. Food Chem. 16, 779 (1968)

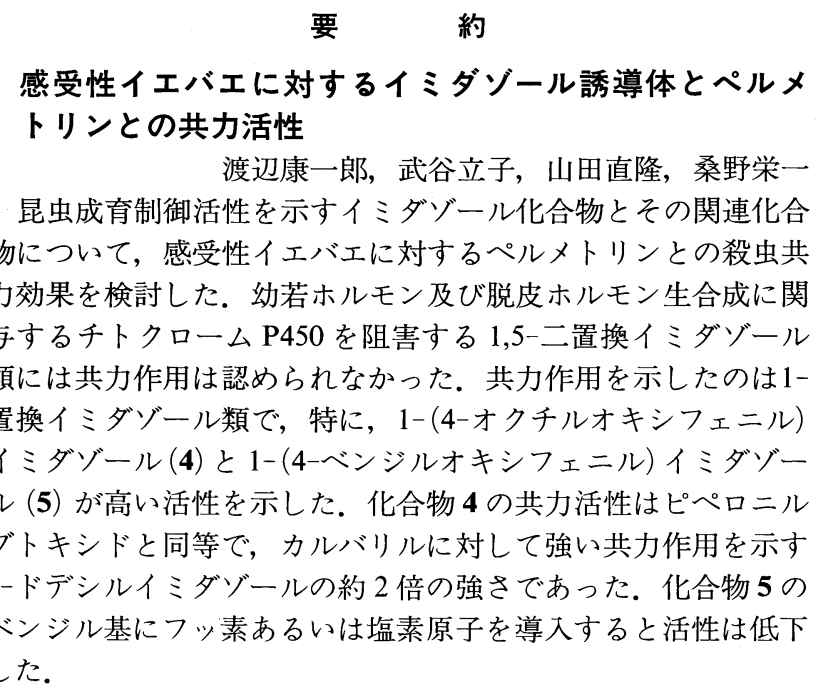

